\title{
Instructional interface's blueprint for guiding instructional-technological interactions' research: the Big Bang shift in K-12
}

\author{
Nayiv Assaf ${ }^{1}$ iD
}

Accepted: 8 November 2020 / Published online: 30 November 2020

(c) Association for Educational Communications and Technology 2020

\begin{abstract}
This response reviews and analyzes the ten focal topics and three elements introduced in Nacu, Martin, and Pinkard's work, entitled "Designing for 21st century learning online: a heuristic method to enable educator learning support roles". An analogy of the London Stock Exchange's Big Bang is drawn to describe the moment education is currently living. In this context, homeschooling guided learning is analyzed. Nacu, Martin, and Pinkard (2018) offered insightful approaches for the sudden shift to digital that the world has experienced since April 2020. Their inquiries coincided with the questions asked by researchers and teachers around the world when their schools were closed due to the COVID-19 lockdown. Along with Nacu et al.'s (EducTech Res 64(4):1029-1049, 2018) effort, a theoretical framework, an instructional interface model, is conceptualized as a blueprint, to offer a guide for research for instructional-technological interactions. In this scenario, shifting to digital is not just a tech shift but a worldwide creators' mindset shifts.
\end{abstract}

Keywords COVID-19 pandemic · Educational Big Bang · Educator-learner interactions · EdTech interface instructionality · Learner-interface interaction · Instructional interface's basic model

The London Stock Exchange switched overnight from paper to computers, this electronic transformation was called the Big Bang. [A dual name either] to create a new universe in a single moment. [Or to the] fears that the whole project would explode. In fact, the Big Bang worked

(Hawkridge 1995, p. 3)

In the first 5 days of April, 2020, 1.725 billion students worldwide were out of the classrooms (COVID-19 Impact 2020) because of the COVID-19 pandemic. So, many of those involved in the educational process turned to mediated education and the technology that makes it possible (Anderson and Rivera-Vargas 2020), seeking a solution to the schools'

Nayiv Assaf

nayiv@tech-center.com

1 Tecnologico de Monterrey, School of Humanities and Education, Ave. Eugenio Garza Sada 2501, 64849 Monterrey, NL, Mexico 
closure (Schlegelmilch and Douglas 2020). Then, the Educational Big Bang (EB $\left.{ }^{2}\right)$, the shifting to digital, suddenly happened.

Today, for the first time in history, education had the technology (Weller 2020) to cope with a lockdown due to a pandemic. However, to face an absolutely unknown educational scenario, it only remains to review the history and guess what may be useful. With a promising and visionary title "designing for the 21 st century learning online", Nacu et al. (2018) put into perspective much of the knowledge available then, which should be useful today, for a successful $\mathrm{EB}^{2}$.

Nacu et al. (2018, p. 1029) developed ten focal topics,

[1] ...growing emphasis on developing 21 st century skills among today's youth...

[2] ...continued optimism about the possibilities granted by increasing access to networked technologies...

[3] ...encouraging youth to pursue their interests and take ownership of their learning...

[4] ...importance of adult support in realizing the promise of achieving these outcomes...

[5] ... designers of ... systems are thus faced with the need to create youth-centered spaces that also provide adult facilitation of learning...

[6] ... adaptation of the traditional heuristic evaluation method.

[7] .... a holistic view of how adult learning support is enabled across the system...

[8] ...how it can be used to help identify areas for improvement and promising areas for further research.

[9] ... a framework of heuristics which reflect specific educator learning support roles that have been found to be important for youth learning, particularly for supporting $21 \mathrm{st}$ century skills.

[10] ...novel heuristic evaluation method that can help designers of online learning platforms attend not only the experiences of learners, but also to how educators are enabled to support their learning.

Nacu et al. (2018, p. 1030)'s work offers "a method to holistically assess how a system enables the educator-learner interactions" kind of interactions they "consider important to support 21st century learning." In this research, three concepts stand out that are useful in situations of shifting to digital within a context of $\mathrm{EB}^{2}$ : (1) the social learning tech factor, at its most basic shape, means that there is a person on both sides of the interface, (2) instructional-technological interaction focus, the easiest way to inform technology-driven learning, and (3) heuristic align approach, the best way to deal with unknown situations or without any background.

Nacu et al. (2018)'s research question became the core question which teachers and researchers around the world asked themselves when implementing the global shift to digital in April, "How can we design ways for adult educators to provide learning support online in a way that also cultivates autonomy and encourages youth as creative producers?" (Nacu et al. 2018, p. 1030). This instructional-technological interaction question on instructional interface design is one of the two big EdTech questions that a research perspective must answer to achieve a successful $\mathrm{EB}^{2}$. Within the $\mathrm{EB}^{2}$ context, Morgan (2020) guides insights to answer it for K-12.

$\mathrm{Nacu}$ et al. (2018)'s vision leads to the second big question that generalizes to diverse interactions' types and EdTech interfaces, how can an EdTech research perspective help us assess the EdTech and Ed-resources' instructionality? The answer must address instructional usability and learner-user experience (Nacu et al. 2018), within 
learner-innterface $i$ nteraction $(\ell \rightleftarrows \mathbb{I})_{i}$ as a discipline and an AI-EdTech envision (Choi 2020) in the form of deep-learned instruction for a suitable solution with enough future tech scope (Assaf et al. 2018).

Nacu et al. (2018)'s method, like most research on interactions, it is limited to a single interaction, the student-interface-educator interaction $(\mathcal{S} \rightleftarrows \ddot{\mathbb{i}} \leftrightarrows \mathrm{e})_{i}$. For this reason, it is essential to have an instructional interface's blueprint (Fig. 1) for guiding instructionaltechnological interactions' researchers, designers, and practitioners for an informed shifting to digital where more than one interaction is involved. A blueprint will help them know where they are, and where and how they want to go along local and wide-range interrelationships among interactions around the instructional interface, and as the integrating axis of elements, structures, means, and solutions between past and future researches.

$\mathrm{EB}^{2}$ put to the test and challenged everything that was known in education. One of the most immediate manifestations was the need for guided learning interaction (Morgan 2020; de Jong and Lazonder 2014), mainly in K-12 (Morgan 2020; Nacu et al. 2018) that required parental involvement with management and outcomes of homeschooling (Fontanesi et al. 2020) at a level that could jeopardize the families' mental and physical health (Fontanesi et al. 2020; Morgan 2020; Varner 2020). This after effect severely contradicted the digital native concept (Kirschner and De Bruyckere 2017). Actually, students, parents, and teachers as well need guidance and support to ensure enough technological-instructional autonomy (Morgan 2020; Kennepohl 2020; Nacu et al. 2018).

Today is the time for globally showing the capacity of everything designed for 21 st century learning online, and proving that tech-mediated teaching and tech-enhanced learning

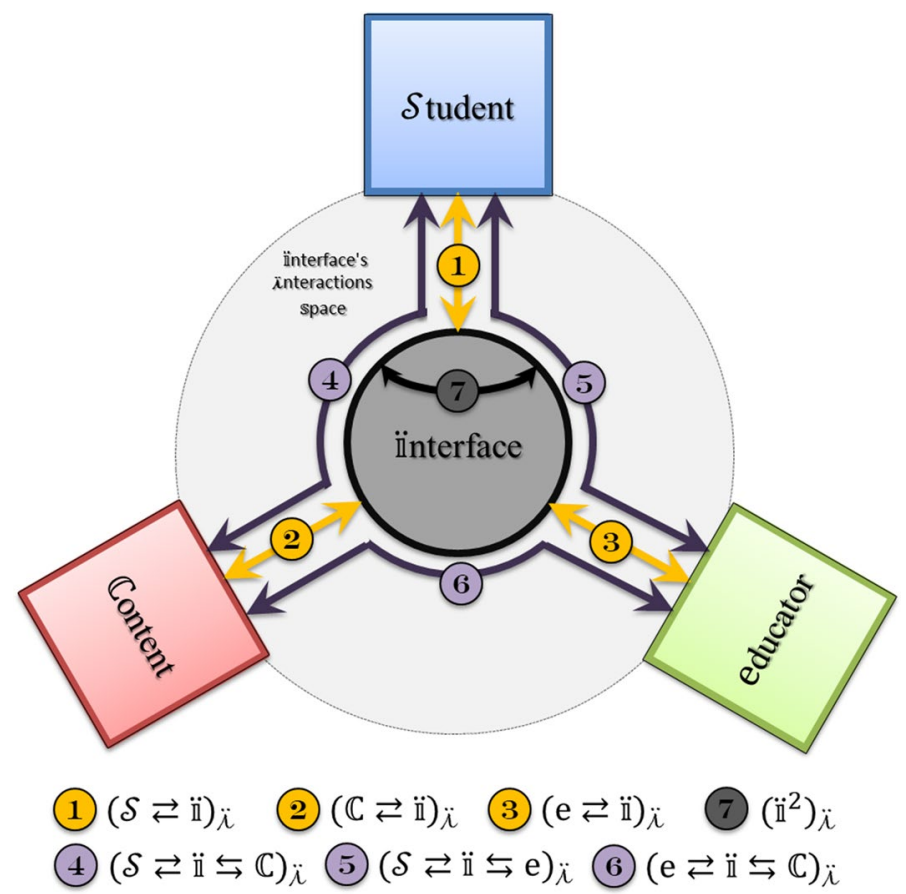

Fig. 1 Blueprint of the instructional interface's basic model 
can offer a type of education as appropriate and at the same level as face-to-face education. Criticisms like "online programs can be implemented poorly" (Morgan 2020, p. 135), must be overcome in the current pandemic situation because the shifting to digital "will get done, because it needs to be done" (Kennepohl 2020, p. i).

Shifting to digital is not just a tech shift. Essentially it is a worldwide creators' mindset shift (Nacu et al. 2018) in all knowledge fields. Because winning our first world war against a non-human species-which unlike what was foreseen by Hollywood, was not an extraterrestrial species-it is a task that involves every teacher and every mind on this planet because it is neither the first nor will it be the last great challenge that education and humanity will have to face.

The $\mathrm{EB}^{2}$ shifting must be for achieving better education and better humanity, and as the London one, the $\mathrm{EB}^{2}$ will work too.

Acknowledgements Thanks to the reviewers for their very appropriate comments to guide the core ideas development of this work. Thanks to the Sociocultural Studies and the AI-EdTech models and applications research subgroups at Tec de Monterrey.

\section{Compliance with ethical standards}

Conflict of interest The author declares that he has no conflict of interest.

Research involving human participants and/or animals This is a theoretical study neither human participants nor animals were involved.

Informed consent This is a theoretical study; no data of any kind was gathered.

\section{References}

Anderson, T., \& Rivera-Vargas, P. (2020). A critical look at educational technology from a distance education perspective. Digital Education Review, 37, 208-229. https://doi.org/10.1344/der.2020.37.208-229.

Assaf, N., Salinas, P., \& Ramírez, D. (2018). Instructional \& technological design for technologically mediated learning milieus, an answer for open technological integration of online lab in today' s STEM classroom. A Gali-plane mobile app case. In EDULEARN18 proceedings, 10th international conference on education and new learning technologies, IATED (pp. 9211-9211). https://doi.org/10.21125/ edulearn.2018.2160.

Choi, G. W. (2020). Reversing explainable AI: Supporting learners' reasoning activities with artificial intelligence. In M. Gresalfi \& I. S. Horn (Eds.), The interdisciplinarity of the learning sciences, 14th international conference of the learning sciences (ICLS) 2020, volume 3. Nashville: International Society of the Learning Sciences. 1522. https://drive.google.com/file/d/101a0JVPKi35fLhilZfnJqIIKaTNnF 9gx/view

COVID-19 Impact on Education. (2020). UNESCO. Retrieved from https://en.unesco.org/covid19/educa tionresponse

de Jong, T., \& Lazonder, A. W. (2014). 15 the guided discovery learning principle in multimedia learning. In R. Mayer (Ed.), The Cambridge handbook of multimedia learning (2nd ed., pp. 371-390). https:// doi.org/10.1017/CBO9781139547369.

Fontanesi, L., Marchetti, D., Mazza, C., Di Giandomenico, S., Roma, P., \& Verrocchio, M. C. (2020). The effect of the COVID-19 lockdown on parents: A call to adopt urgent measures. Psychological Trauma: Theory, Research, Practice, and Policy, 12(S1), S79-S81. https://doi.org/10.1037/tra0000672S79.

Hawkridge, D. (1995). The big bang theory in distance education. In F. Lockwood (Ed.), Open and distance learning today (pp. 3-12). https://eric.ed.gov/?id=ED389922

Kennepohl, D. (2020). Editorial. The International Review of Research in Open and Distance Learning, 21(2), i-iii. https://doi.org/10.19173/irrodl.v21i2.4812. 
Kirschner, P. A., \& De Bruyckere, P. (2017). The myths of the digital native and the multitasker. Teaching and Teacher Education, 67, 135-142. https://doi.org/10.1016/j.tate.2017.06.001.

Morgan, H. (2020). Best practices for implementing remote learning during a pandemic. The Clearing House: A Journal of Educational Strategies, Issues and Ideas, 93(3), 135-141. https://doi. org/10.1080/00098655.2020.1751480.

Nacu, D., Martin, C. K., \& Pinkard, N. (2018). Designing for 21st century learning online: A heuristic method to enable educator learning support roles. Educational Technology Research and Development, 66(4), 1029-1049. https://doi.org/10.1007/s11423-018-9603-0.

Schlegelmilch, J., \& Douglas, C. (2020). Initial COVID-19 closure strategies adopted by a convenience sample of US school districts: Directions for future research. Disaster Medicine and Public Health Preparedness, 1-4. https://doi.org/10.1017/dmp.2020.147.

Varner, C. (2020). Parents on the front lines of COVID-19 face tough choices. CMAJ, 192(17), E467-E468. https://doi.org/10.1503/cmaj.1095864.

Weller, M. (2020). 25 years of ed tech. Athabasca University Press. https://www.aupress.ca/books/12029 0-25-years-of-ed-tech/

Publisher's Note Springer Nature remains neutral with regard to jurisdictional claims in published maps and institutional affiliations.

Nayiv Assaf is an educational technologist and a Ph.D. candidate in educational innovation at Tec de Monterrey, is an instructional designer and technology developer of technological learning environments for STEM, his current research line is the interactive multimedia design instructionality assessment of technological interfaces and interaction in the Learner-Interface Interaction framework. He belongs to the AIEdTech models and application research subgroup at Tecnológico de Monterrey. 